\title{
Vibration-induced white fingers and manipulative dexterity
}

\author{
P. A. BANISTER and F. V. SMITH \\ Department of Psychology, University of Durham
}

\begin{abstract}
Banister, P. A., and Smith, F. V. (1972). Brit. J. industr. Med., 29, 264-267. Vibration-induced white fingers and manipulative dexterity. Previous work has shown that Raynaud's phenomenon or vibration-induced white fingers are associated with consistent use of vibrating tools. The present study indicates that significant losses in manipulative skill are also associated with the use of power-driven saws when groups of users and non-users are compared.
\end{abstract}

Since Raynaud (1862) described a vascular disorder affecting mainly young women, intermittent attacks of cold-induced pallor or cyanosis of the extremities have been generally described as Raynaud's phenomenon. Similar vascular disturbances have been noted in the hands of workers using vibrating tools in many occupations, and these disturbances have been described as 'Raynaud's phenomenon caused by the use of vibrating tools' or, as the Industrial Injuries Advisory Council (1970) now call it,'vibration-induced white fingers' (VWF).

Research has indicated that a high proportion of consistent users of vibrating tools (especially under cold conditions) suffer from VWF. Marshall, Poole, and Reynard (1954), for example, indicated that men using pneumatic and trip hammers revealed motor weakness, sensory loss, and premature, subjective numbness in response to experimentally induced ischaemia. Follow-up studies have also shown that such effects are likely to be long-lasting, and clearly apparent after several years. One such study is that of Agate (1949), who found that $66.2 \%$ of his sample of 278 factory workers using rotary scurfing and polishing tools suffered from VWF, and that $88.6 \%$ of the 189 workers of this sample, who replied to his questionnaire two and a half years later, reported VWF. The three main theories in this field all stress that changes are likely to be relatively irreversible as they associate the physiological nature of the disorder with either vascular lesions, persistent nerve damage (probably a disturbance of vasomotor control), or callus formation.

Despite these findings VWF studies have apparently been constrained by 'the feeling that its strikingly visible effects can easily be exaggerated in importance' (McCallum, 1971), and it is relevant to mention that the Industrial Injuries Advisory Council (1970) did not consider VWF to be sufficiently disabling to justify prescription under the National Insurance (Industrial Injuries) Act 1965. This may be because research has generally been confined to the vascular disturbances alone, while additional symptoms, such as loss of sensation in fingers affected by vibration, weakness of the grip, and loss of power in the muscles have been described by some writers (e.g., Reynard, 1954; Marshall et al., 1954) but have not been extensively followed up. It is hoped that the following data from tests of manipulative dexterity may be of some interest in this context.

\section{Method}

\section{Selection of subjects}

In the course of an enquiry into the effects of different occupations on the pattern of responses to a variety of psychological tests, 77 men were tested on the following battery of tests:

(1) a psychomotor test; the Gibson Spiral Maze (Gibson, 1965); 
(2) a test of spatial ability; the General Aptitude Test Battery (1968) Form Matching subtest;

(3) memory tests; the Visual Reproduction and Associate Learning subtests of the Wechsler Memory Scale (Wechsler and Stone, 1945);

(4) a test of manipulative dexterity; the Purdue Pegboard (Tiffin, 1968);

(5) verbal and performance intelligence tests; the Wechsler Adult Intelligence Scale (Wechsler, 1955), which consists of 11 separately scored subtests (Information, Comprehension, Arithmetic, Similarities, Digit Span, Vocabulary, Digit Symbol, Picture Completion, Block Design, Picture Arrangement, and Object Assembly);

(6) visual reaction-time tests; these tests measured the time subjects took to respond to a light by pressing a lever, under three conditions; simple response to one light, choice reaction to two lights and reversed choice (moving lever in opposite direction).

These men were chosen to provide a sample of varying ages from both rural and urban backgrounds, predominantly manual and semiskilled workers, and of approximately equal socio-economic status. Among the men tested, there were 24 who had regularly used power saws, and it was decided to use these subjects in a study of VWF with the exclusion of two who had lost fingers in accidents involving saws, thereby making a sample of 22 saw-users. The scores on the Purdue Pegboard, which purports to measure manipulative dexterity, being the major point of interest, a group of 46 non-saw users was selected by the following procedure; the total correlation matrix for the results of the saw-users on all the tests was examined, and where a significant correlation between a test result and a Purdue Pegboard result occurred (Table 1), subjects were selected so that there was no significant difference between the means for that particular test or in the age of the groups of saw and non-saw users (Table 2).
TABLE 2

Differences between Means of Two Groups for VARIABLES SigNIFICANTLY CORRELATED WITH Purdue Pegboard Scores

\begin{tabular}{|c|c|c|c|c|c|c|}
\hline & & & & $\begin{array}{c}\text { Saw } \\
\text { operators }\end{array}$ & $\begin{array}{l}\text { Control } \\
\text { group }\end{array}$ & $\mathbf{t}$ \\
\hline \multicolumn{4}{|c|}{ Form matching } & & & \multirow{3}{*}{0.502} \\
\hline Mean & & & .. & $28 \cdot 864$ & $29 \cdot 739$ & \\
\hline Standa & $d d$ & ation & . & $6 \cdot 372$ & $7 \cdot 410$ & \\
\hline \multicolumn{4}{|c|}{ Visual reproduction } & & & \multirow{3}{*}{$0 \cdot 370$} \\
\hline Mean & & . & . & $10 \cdot 045$ & $9 \cdot 783$ & \\
\hline SD & & .. & .. & $2 \cdot 734$ & $2 \cdot 732$ & \\
\hline \multicolumn{6}{|c|}{ Digit symbol } & \multirow{3}{*}{$0 \cdot 254$} \\
\hline Mean & & $\ldots$ & . & $8 \cdot 682$ & $8 \cdot 826$ & \\
\hline SD & & . & . & $2 \cdot 255$ & $2 \cdot 036$ & \\
\hline \multicolumn{6}{|c|}{ Picture completion } & \multirow{3}{*}{$0 \cdot 394$} \\
\hline Mean & & . & . & $12 \cdot 500$ & $12 \cdot 739$ & \\
\hline SD & & .. & . & $3 \cdot 189$ & $2 \cdot 577$ & \\
\hline \multicolumn{6}{|c|}{ Block design } & \multirow{3}{*}{$1 \cdot 046$} \\
\hline Mean & & . & $\cdots$ & $11 \cdot 682$ & $10 \cdot 826$ & \\
\hline SD & & 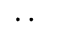 & . & $3 \cdot 286$ & $2 \cdot 870$ & \\
\hline \multicolumn{6}{|c|}{ Picture arrangement } & \multirow{3}{*}{0.499} \\
\hline Mean & .. & .. & $\ldots$ & $9 \cdot 955$ & $9 \cdot 630$ & \\
\hline SD & & .. & .. & $2 \cdot 380$ & $2 \cdot 768$ & \\
\hline \multicolumn{6}{|c|}{ Performance IQ } & \multirow{3}{*}{0.097} \\
\hline Mean & . & .. & . & $106 \cdot 682$ & $106 \cdot 968$ & \\
\hline SD & & & . & $11 \cdot 716$ & $11 \cdot 383$ & \\
\hline \multicolumn{6}{|c|}{ Choice reaction time } & \multirow{4}{*}{$1 \cdot 509$} \\
\hline Mean & . & .. & . & 0.343 & $0 \cdot 365$ & \\
\hline SD & & .. & . & 0.056 & 0.054 & \\
\hline \multicolumn{4}{|c|}{$\begin{array}{l}\text { Reversed choice reaction } \\
\text { time }\end{array}$} & & & \\
\hline Mean & . & . & $\cdots$ & $0 \cdot 451$ & 0.515 & $1 \cdot 742$ \\
\hline SD & 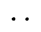 & . & . & $0 \cdot 136$ & $0 \cdot 150$ & \\
\hline
\end{tabular}

All not significant.

Correlations between Purdue Pegboard Scores and Other Variables for the Saw Users $(\mathrm{N}=22)$

\begin{tabular}{|c|c|c|c|c|c|c|c|c|}
\hline & \multicolumn{8}{|c|}{ Purdue Pegboard } \\
\hline & $\begin{array}{c}\text { Initial } \\
\text { practice }\end{array}$ & $\begin{array}{l}\text { Dominant } \\
\text { hand (D) }\end{array}$ & $\begin{array}{c}\text { Non- } \\
\text { dominant } \\
\text { hand (ND) }\end{array}$ & $\begin{array}{l}\text { Both } \\
\text { hands } \\
\text { (B) }\end{array}$ & $\begin{array}{c}\text { Total } \\
\text { sample } \\
(\mathrm{D}+\mathrm{ND}+\mathrm{B})\end{array}$ & $\begin{array}{l}\text { Assembly } \\
\text { trial } \\
\text { I }\end{array}$ & $\begin{array}{c}\text { Assembly } \\
\text { trial } \\
\text { II }\end{array}$ & $\begin{array}{c}\text { Total } \\
\text { assembly } \\
(\mathrm{I}+\mathrm{II})\end{array}$ \\
\hline $\begin{array}{l}\text { Form matching (General } \\
\text { Aptitude Test Battery) }\end{array}$ & 0.47 & $0 \cdot 46$ & $0 \cdot 50$ & $0 \cdot 49$ & $0 \cdot 53$ & $0 \cdot 50$ & 0.47 & $0 \cdot 49$ \\
\hline $\begin{array}{l}\text { Visual reproduction } \\
\text { (Wechsler Memory Scale). . } \\
\text { Wechsler Adult Intelligence }\end{array}$ & $0 \cdot 29$ & $0 \cdot 27$ & $0 \cdot 50$ & $0 \cdot 22$ & $0 \cdot 37$ & 0.48 & 0.45 & 0.47 \\
\hline Scale-Digit Symbol & 0.45 & 0.55 & 0.49 & 0.57 & 0.59 & $0 \cdot 46$ & 0.54 & 0.51 \\
\hline Picture completion .. & $0 \cdot 34$ & $0 \cdot 32$ & 0.55 & $0 \cdot 40$ & 0.46 & $0 \cdot 38$ & $0 \cdot 37$ & $0 \cdot 38$ \\
\hline Block design ... & 0.40 & $0 \cdot 38$ & $0 \cdot 33$ & $0 \cdot 30$ & $0 \cdot 38$ & $0 \cdot 50$ & $0 \cdot 50$ & $0 \cdot 51$ \\
\hline Picture arrangement .. & 0.42 & $0 \cdot 31$ & $0 \cdot 25$ & $0 \cdot 32$ & $0 \cdot 32$ & 0.44 & $0 \cdot 36$ & $0 \cdot 40$ \\
\hline Performance IQ $\quad$. . & $0 \cdot 50$ & 0.46 & $0 \cdot 50$ & 0.50 & 0.54 & 0.55 & $0 \cdot 54$ & 0.55 \\
\hline Choice reaction time.. & $-0 \cdot 53$ & -0.41 & $-0 \cdot 50$ & -0.39 & -0.48 & -0.43 & $-0 \cdot 35$ & $-0 \cdot 39$ \\
\hline Reversed choice reaction time & -0.29 & $-0 \cdot 37$ & $-0 \cdot 32$ & $-0 \cdot 30$ & $-0 \cdot 37$ & -0.59 & -0.49 & -0.54 \\
\hline
\end{tabular}

$r \pm 0.43$ or more is significant at the 0.05 level. 
Test used

Purdue Pegboard (Tiffin, 1968) The first part of this test consists of three simple tasks, involving the placing of metal pegs as quickly as possible into holes on a board, using first the dominant hand only, then the nondominant hand only, and finally both hands together; scores consist of the number of pegs placed in the holes in 30 seconds. A preliminary study found no significant improvement on the simple tasks over three trials so it was decided to follow the standard one-trial procedure, with the addition of an initial scored practice trial, to familiarize subjects with the test. The second part of this test consists of assembling items (pegs, washers, and sleeves); the number of items correctly placed on the board in 60 seconds is scored. The preliminary study found a significant improvement $(P<0.05)$ only between first and second trials and, accordingly, this test was administered twice.

Testing procedure

The Purdue test was individually administered as part of a two-hour private testing session, standard instructions being used, and came at least half an hour after the start of the testing session. In this time the men were actively using their hands in tasks involving pencils and paper and thus had some opportunity to 'limber up'. They were tested during the period May 1969 to December 1970; the saw-users were tested between May and November 1969 , the bulk of them being seen by July 1969 . All testing sessions were conducted in heated rooms. The weather was generally warm, and testing did not start until well into the working day; at no time did spasms occur during testing, although several men indicated that they had previously suffered from them.

\section{Results}

(As the hypothesis being tested is that prolonged use of power saws will, if of any influence at all, have an adverse affect on manipulative dexterity, one-tailed $t$-tests of significance were used in this study.)

The saw operators completed fewer items on all the Purdue Pegboard items, with the exception of the non-dominant hand-test, and were significantly below the control group on the initial practice test $(P<0.05)$ and the dominant hand-test $(P<0.02)$.

\section{Conclusion and discussion}

The results (Table 3 ) indicate that the prolonged use of vibrating tools may have discernible effects on fine, manipulative skills, significant differences and consistent trends being found between the scores of power saw-users and the scores of non saw-users on a standard psychological test of manipulative dexterity. The dominant hand tends to be the most affected. It is possible that the vibration characteristics may vary with different models of saw, but the impression gained by the authors in using a power-saw was that the dominant hand, normally tensed in holding the trigger grip and directly behind the two-stroke motor and cutting track, absorbed the greater vibration. These results are comparable with those of Agate (1949), who found the greatest effects of the use of vibrating tools on the hand which received the most vibration, and supported again by the findings of Marshall et al.

TABLE 3

Results on Purdue Pegboard

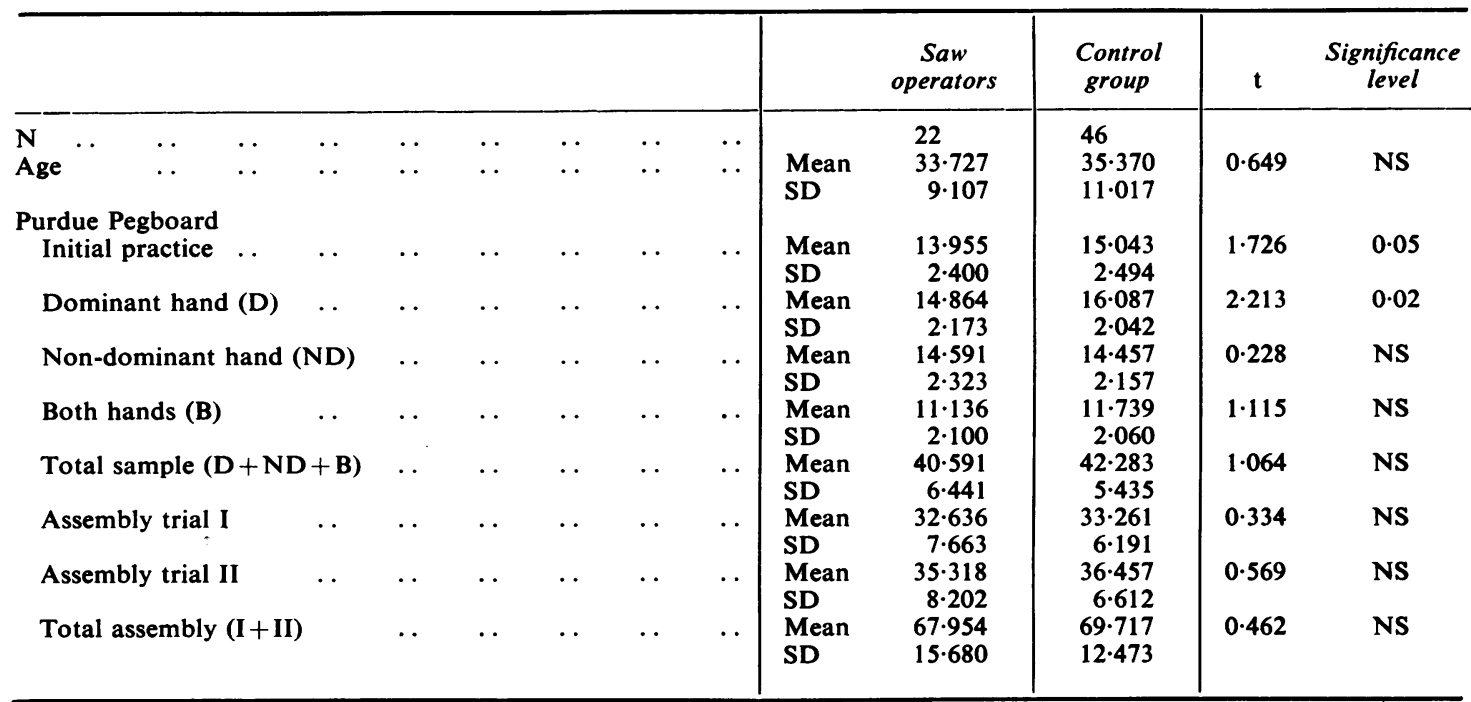

NS $=$ not significant. 
(1954), who found that in several of their cases who had used pneumatic hammers, the condition was entirely unilateral.

The foregoing results indicate that a decline in performance in tasks involving fine manipulation should be included among the possible sequelae of the prolonged use of vibrating tools which are held in the hands.

\section{References}

Agate, J. N. (1949). An outbreak of cases of Raynaud's phenomenon of occupational origin. Brit. J. industr. Med., 6, 144-163.

General Aptitude Test Battery (1968). Manual. United States Department of Labor, Washington.

Gibson, H. B. (1965). Manual of the Gibson Spiral Maze. University of London Press, London.

Industrial Injuries Advisory Council (1970). Vibration Syndrome. Cmnd 4430. H.M.S.O., London.
McCallum, R. I. (1971). Vibration syndrome. Brit. J. industr. Med., 28, 90-93.

Marshall, J., Poole, E. W., and Reynard, W. A. (1954). Raynaud's phenomenon due to vibrating tools; neurological observations. Lancet, 1, 1151-1156.

Raynaud, M. (1862). On local asphyxia and symmetrical gangrene of the extremities. In: Barlow, T. (1888). Selected Monographs. New Sydenham Society, London.

Reynard, W. A. (1954). Effects of vibrating machines. In: British Encyclopedia of Medical Practice, Interim Supplement (February). Butterworth, London.

Stewart, A. M., and Goda, D. F. (1970). Vibration syndrome. Brit. J. industr. Med., 27, 19-27.

Tiffin, J. (1968). Purdue Pegboard Examiner Manual. Science Research Associates, Chicago.

Wechsler, D. (1955). Manual for the Wechsler Adult Intelligence Scale. Psychological Corporation, New York.

, and Stone, C. P. (1945). Wechsler Memory Scale Manual. Psychological Corporation, New York.

Received for publication December 3, 1971. 